\title{
Orthodontic Management of Silver-Russell Syndrome. A Case Report
}

\author{
Ioulia Ioannidou-Marathiotou ${ }^{*}$, Ariel Sluzker and Athanasios E. Athanasiou
}

Department of Orthodontics, School of Dentistry, Aristotle University of Thessaloniki, Greece

\begin{abstract}
This case report describes the orthodontic management of a 10-year-old female with Silver-Russell syndrome by means of gradual expansion of the mandibular dental arch using removable appliances and subsequent comprehensive treatment of malocclusion by means of fixed appliances.
\end{abstract}

Keywords: Silver-Russell syndrome, orthodontics.

\section{INTRODUCTION}

The Silver-Russell (SR) syndrome is a single entity, characterized by prenatal growth deficiency and postnatal dwarfism. The incidence is $1 / 100.000$ live births [1] and the chromosomes consistently implicated are the 7 and the 17 [2]. Criteria for diagnosis include intrauterine and postnatal growth retardation, limb asymmetry, and triangular shaped face. Other features occasionally associated include down turned corners of the mouth, fifth finger clinodactyly, lowset ears, weak muscle tone, blue sclera, café-au-lait spots, and achromic patches. There are thus a plethora of manifested indicators associated with the SR syndrome [1, 3-11].

The craniofacial morphology involves frontal bossing, a reduced length of the total cranial base, small linear facial dimensions, decreased posterior facial height, mandibular retrognathia and reduced mandibular measurements [12-14]. In one study this pattern was different since the mandibular body length was reduced, perhaps due to a Class III skeletal pattern of a patient with a large mandible, influencing the mean values of the measurements [15].

The dental manifestations reported are microdontia, congenital absence of lateral incisors and second premolars, presence of primary double molar tooth, and more consistently relevant, crowding of the teeth, especially in the mandible [13, 15-18].

The bibliography concerning management of oro-facial deformities of patients with SR syndrome seems to be sparse. Kisnisci et al. [19], presented a case with severe mandibular hypoplasia, marked Class II, division 1 malocclusion and crowding, which was treated by means of distraction osteogenesis of the midsymphysis to widen the mandible in concert with bilateral sagittal split ramus osteotomy for mandibular advancement. These skeletal changes facilitated the orthodontic treatment in an optimal manner thus successfully achieving optimal occlusion and an or

*Address correspondence to this author at the Ioulia Ioannidou-Marathiotou, Associate Professor, Department of Orthodontics, School of Dentistry, Aristotle University of Thessaloniki, Agiou Dimitriou Street, 54124 Thessaloniki, Greece; Tel.: +30 2310 999483; Fax: +30 2310 999549;

E-mail: ioannidou@dent.auth.gr thognathic profile. This article describes the orthodontic management of a 10-year-old female with Silver-Russell syndrome.

\section{CASE PRESENTATION}

A 10-year-old Caucasian female, requested treatment at the Postgraduate Orthodontic Clinic of the Aristotle University of Thessaloniki. The main concern of parents and the patient was the presence of malocclusion, which created esthetic and psychological problems.

Medical history and records revealed the presence of a SR syndrome, which was diagnosed 9 months after patient's birth, when she was hospitalized for dystrophy, anorexia and a persistent high fever. According to her medical history, growth hormone was never administered to the patient during her childhood.

During the clinical examination the patient presented a short stature $(142 \mathrm{~cm})$, leg asymmetry of $4 \mathrm{~cm}$, smooth clinodactyly and a small size of the fifth finger in both hands. No mental retardation was noticed.

Examination revealed a triangular face with low set moderately protrusive asymmetrical ears, the right being in a lower position than the left. The mandible was small, the corners of the mouth were turned down, and the upper central incisors were moderately exposed. The lateral facial view revealed a convex profile. Panoramic radiography showed the presence of all permanent teeth (Fig. 1). However, the patient presented delayed dental eruption. At the age of 10 years, she was on early mixed dentition (stage A), with normal eruption of upper and lower incisors only. The $1^{\text {st }}$ left and right lower molars were insufficiently erupted, in particular the right, which was fully covered by tissue, and the $1^{\text {st }}$ upper molars had not yet erupted.

There was a Class I occlusal relationship on the left side. Although molar relationships on the right side could not be clinically assessed because of the buccal occlusion and the excessive overbite, which masked dental relations, examination of dental casts revealed a Class II relationship. The upper arch was slightly crowded, but the lower presented severe crowding, with the lower lateral incisors being displaced in a lingual position. There was a normal overjet, in- 

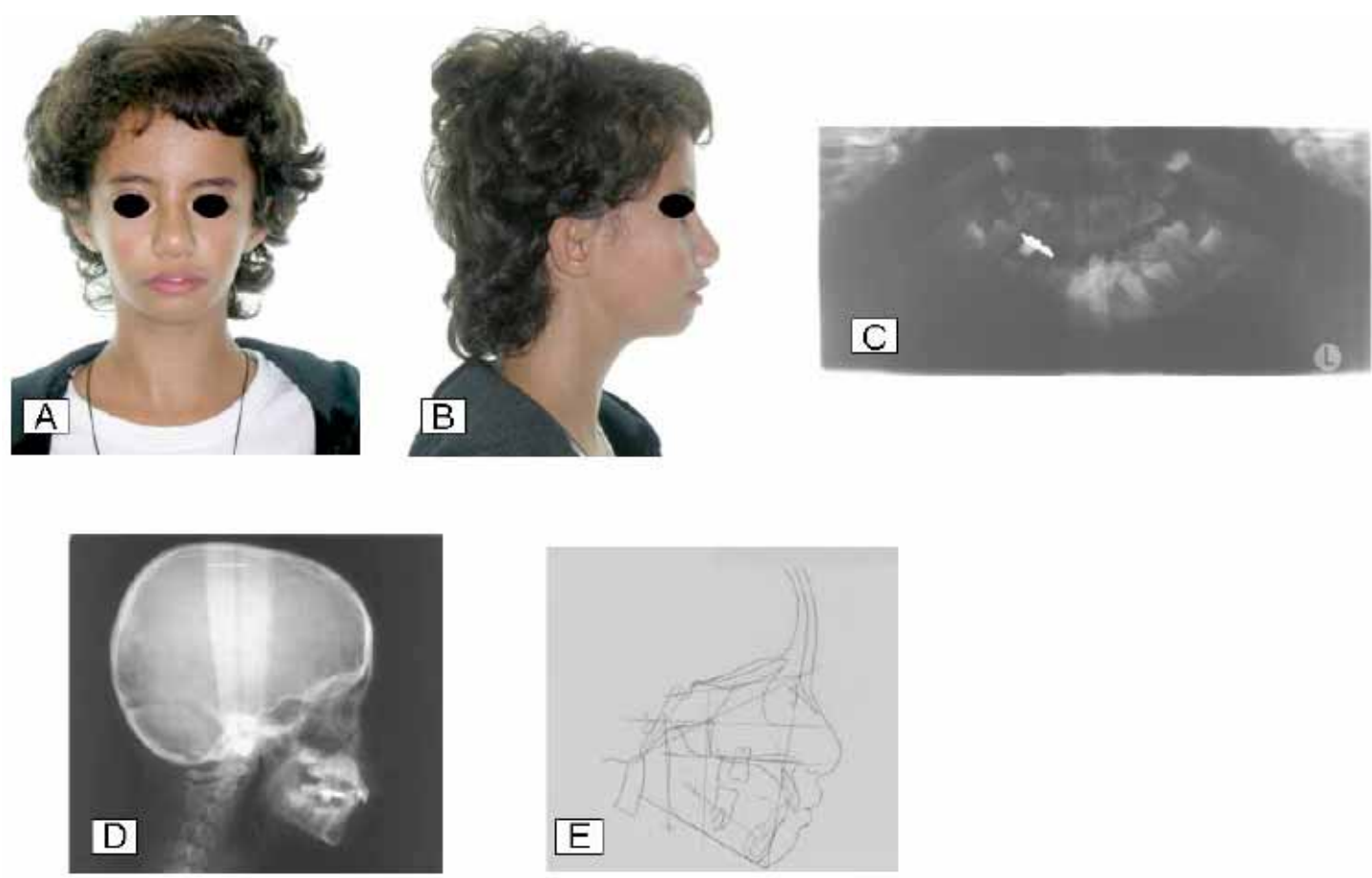

Fig. (1). Pre-treatment frontal (A) and lateral (B) views, panoramic radiograph (C), lateral cephalometric radiography (D), and its corresponding tracing $(\mathbf{E})$.
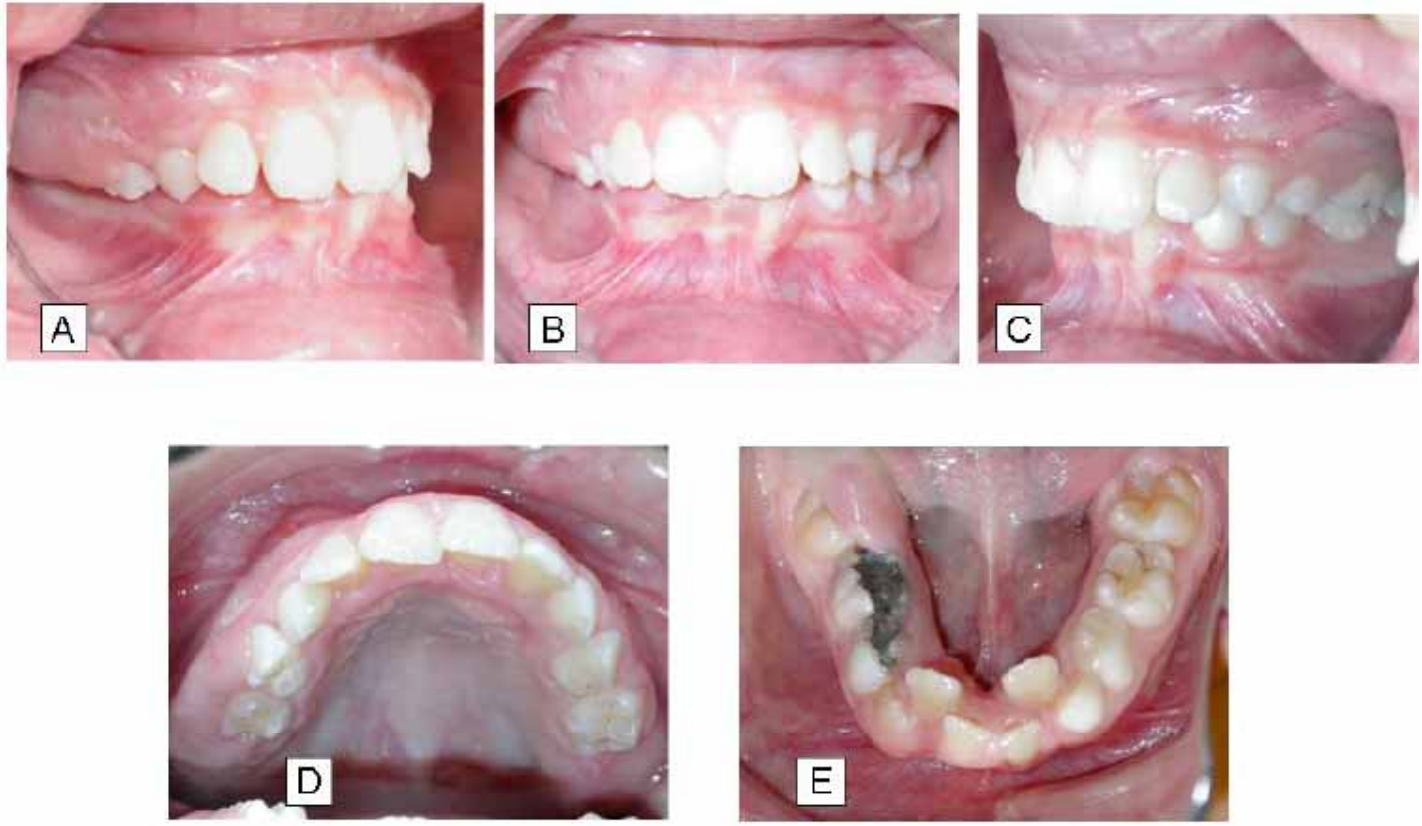

Fig. (2). Pre-treatment intraoral views of dental relations: A, right side; B, frontal; C, left side; D, occlusal view of maxillary dental arch; E, occlusal view of mandibular dental arch.

creased overbite, transverse discrepancy of the mandible in relation to the maxilla as well as lower dental arch midline deviation of $2 \mathrm{~mm}$ to the left side (Fig. 2).

Lateral radiographic cephalometric evaluation revealed a dolichofacial growth pattern, the main skeletal abnormalities being the slightly increased mandibular plane, the posterior position of mandible, the decreased mandibular length and the increased facial convexity. Soft tissue profile cephalometric analysis showed a slightly anterior position of the lower lip according to the esthetic plane.
Overall diagnosis noted a Class II, division 1, subdivision malocclusion in a Class II skeletal pattern.

As a first step before commencing orthodontic treatment, the patient was referred for surgical exposure of the right $1^{\text {st }}$ permanent lower molar. Then, two phases of orthodontic management took place. During the first phase a conventional tooth borne removable appliance with a median screw for expansion of the mandibular arch was used. The screw was activated $0,5 \mathrm{~mm} /$ week. After 20 months, a significant widening of the lower dental arch had been achieved. The 

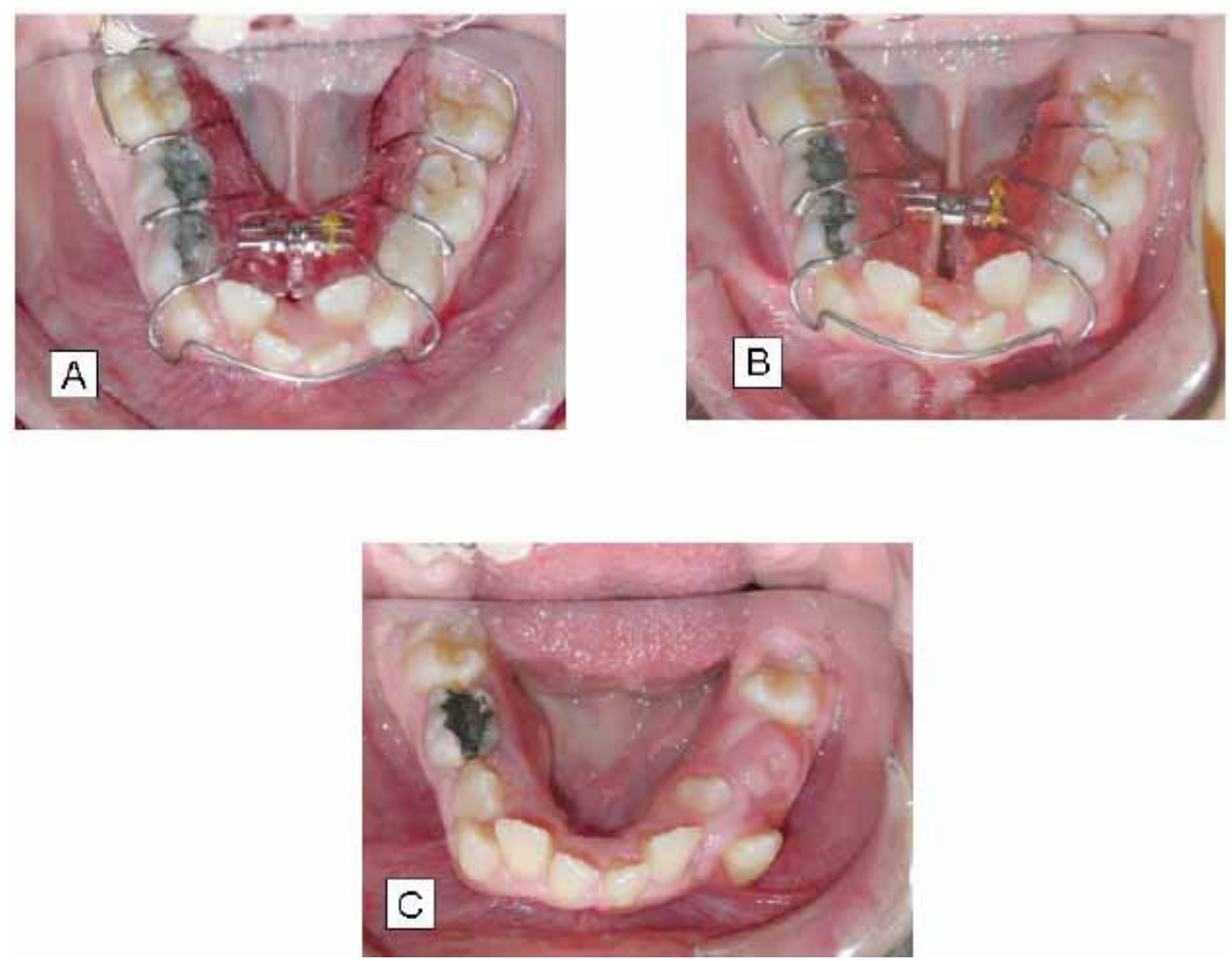

Fig. (3). Orthodontic treatment of the mandibular dental arch by means of removable expansion appliance at the beginning of treatment (A), after 7 months $(\mathbf{B})$, and after 20 months $(\mathbf{C})$.
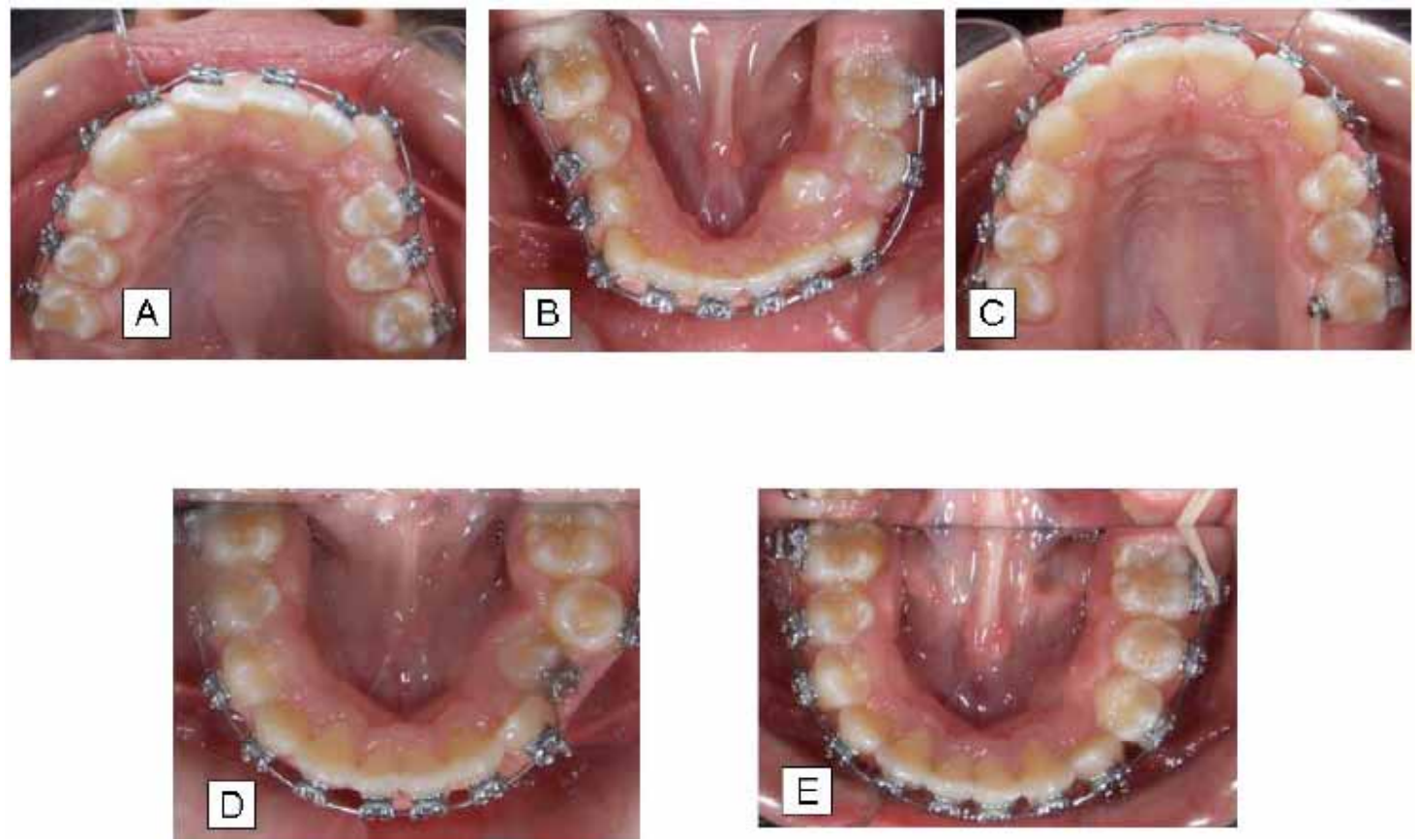

Fig. (4). Different stages and views of comprehensive orthodontic treatment by means of fixed appliances in both dental arches (A, B, C, D, E).

lower incisors were gradually moved forward into a better position and the transverse discrepancy as well as the buccal occlusion had been improved (Fig. 3). Major problems occurring during the period of expansion, were the ectopic appearance of the left lower canine, the movement of the left $1^{\text {st }}$ lower premolar to a lingual position together with rotation, and the need for surgical exposure of the $2^{\text {nd }}$ premolar, which compromised the stability and the efficiency of the removable expansion appliance.

During the second phase, a non-extraction orthodontic treatment by means of fixed appliances was performed for alignment, leveling, coordination and finishing of the dental arches (Fig. 4). At the end of the treatment optimum occlusal 

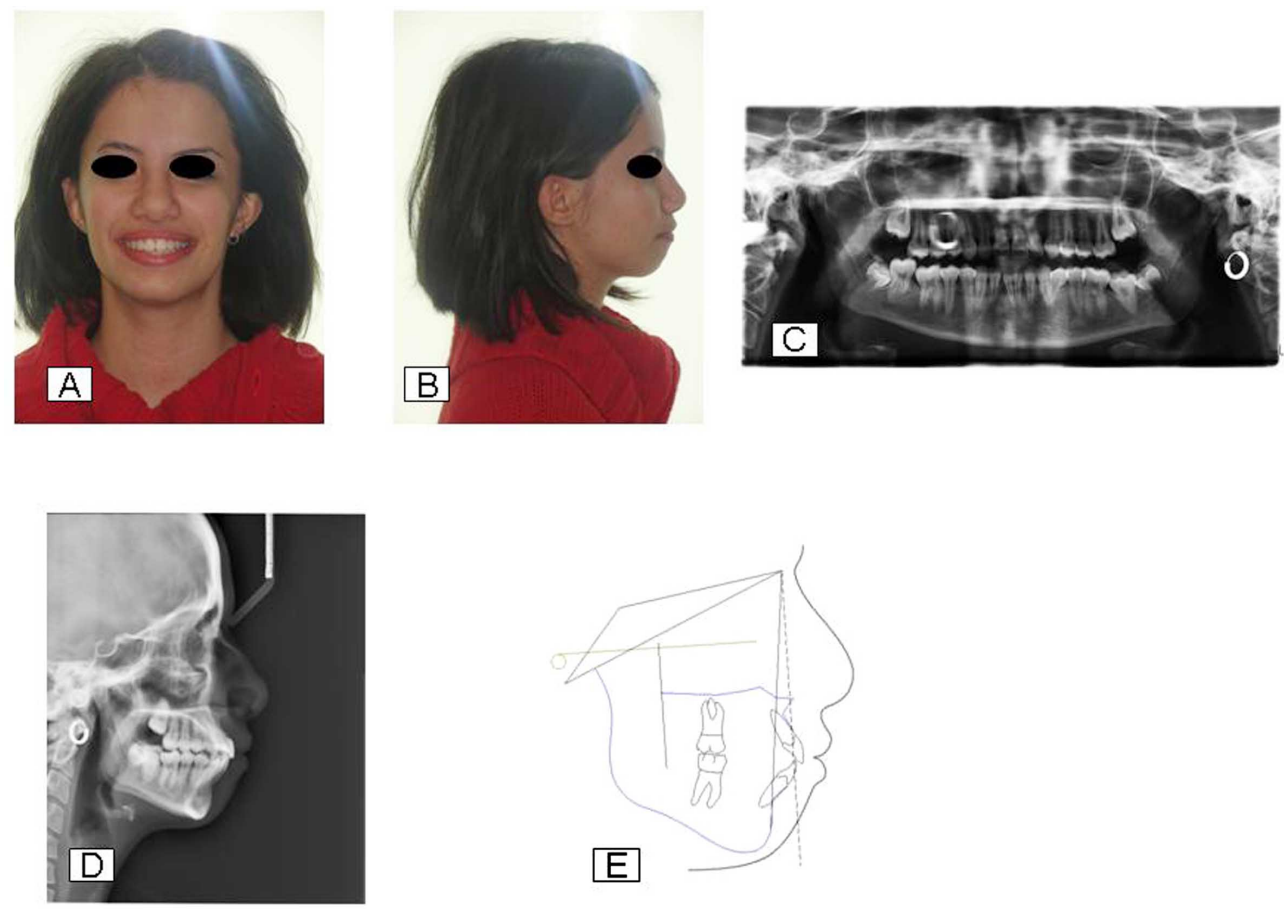

Fig. (5). Post-treatment frontal (A) and lateral (B) views, panoramic radiography (C), lateral cephalometric radiography (D), and its corresponding tracing $(\mathbf{E})$.
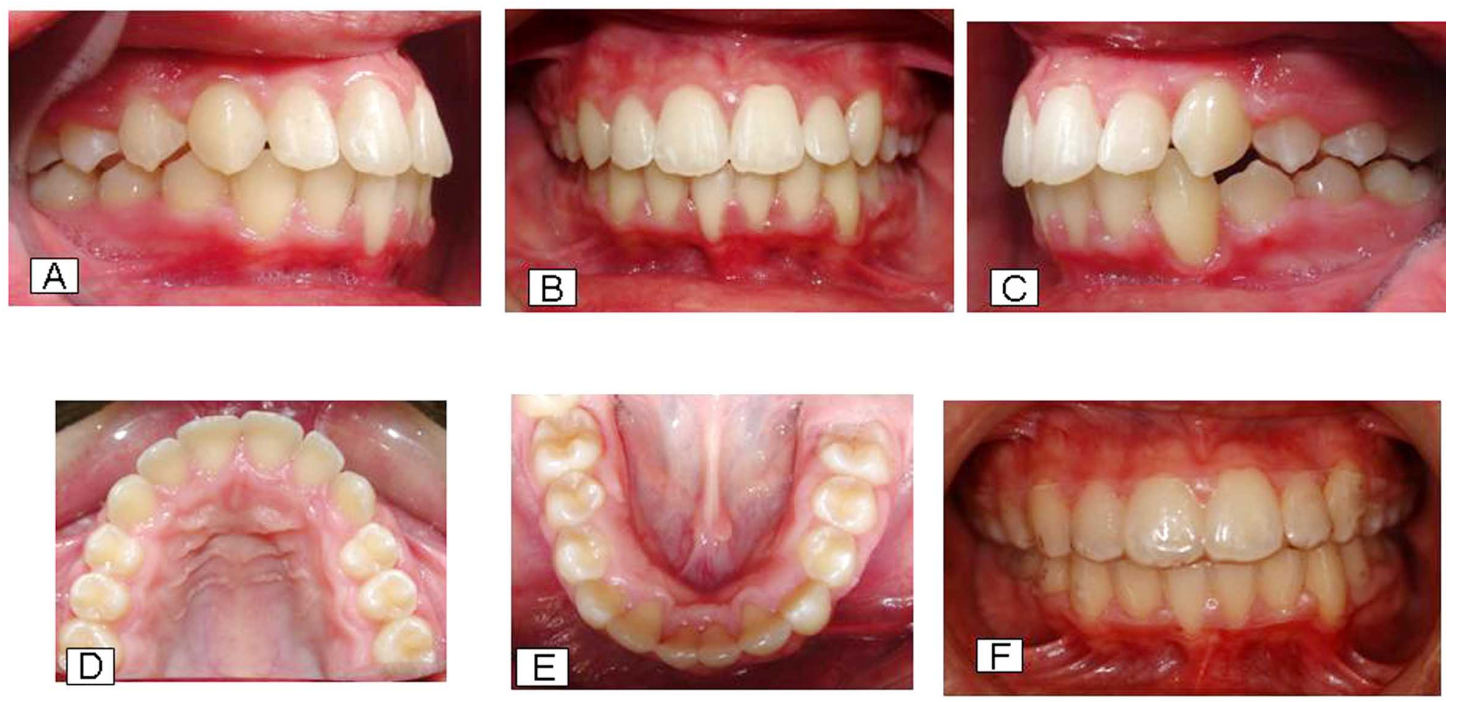

Fig. (6). Post-treatment intraoral views of dental relations: A, right side; $\mathbf{B}$, frontal; $\mathbf{C}$, left side; $\mathbf{D}$, occlusal view of maxillary dental arch; E, occlusal view of mandibular dental arch; and $\mathbf{F}$, with Essix ${ }^{\mathrm{R}}$ retainers in both dental arches.

and skeletal relationships were present (Fig. 5). Frontal and lateral face views showed also an acceptable appearance. Main findings in the post-treatment lateral cephalometric analysis included small anterior mandibular rotation, decrease of lower facial height, proclination of lower incisors, and increase of the nasolabial angle (Fig. 6).

Following removal of orthodontic appliances, the patient was instructed to wear removable Essix retainers. Regular examinations during the retention period (every six months) indicate that the patient presents good stability of the occlusion. At the age of 17 years, mandibular right $2^{\text {nd }}$ molar is partially erupted. At this age small changes were noticed on the posterior occlusion, which maybe are due to the dental arch coverage by the thermoplastic retainers or/and the eruption of the $2^{\text {nd }}$ mandibular molar (Fig. 7).

\section{DISCUSSION}

The patient with SR syndrome of this case report received a non-surgical conservative orthodontic treatment approach. Firstly by expanding the mandibular dental arch using conventional removable appliances with a median screw, and secondly by utilizing fixed orthodontic appliances in order to correct the problems of tooth malalignment and malposition. There were two main reasons for this decision. The first reason was that despite presenting the typical V- 

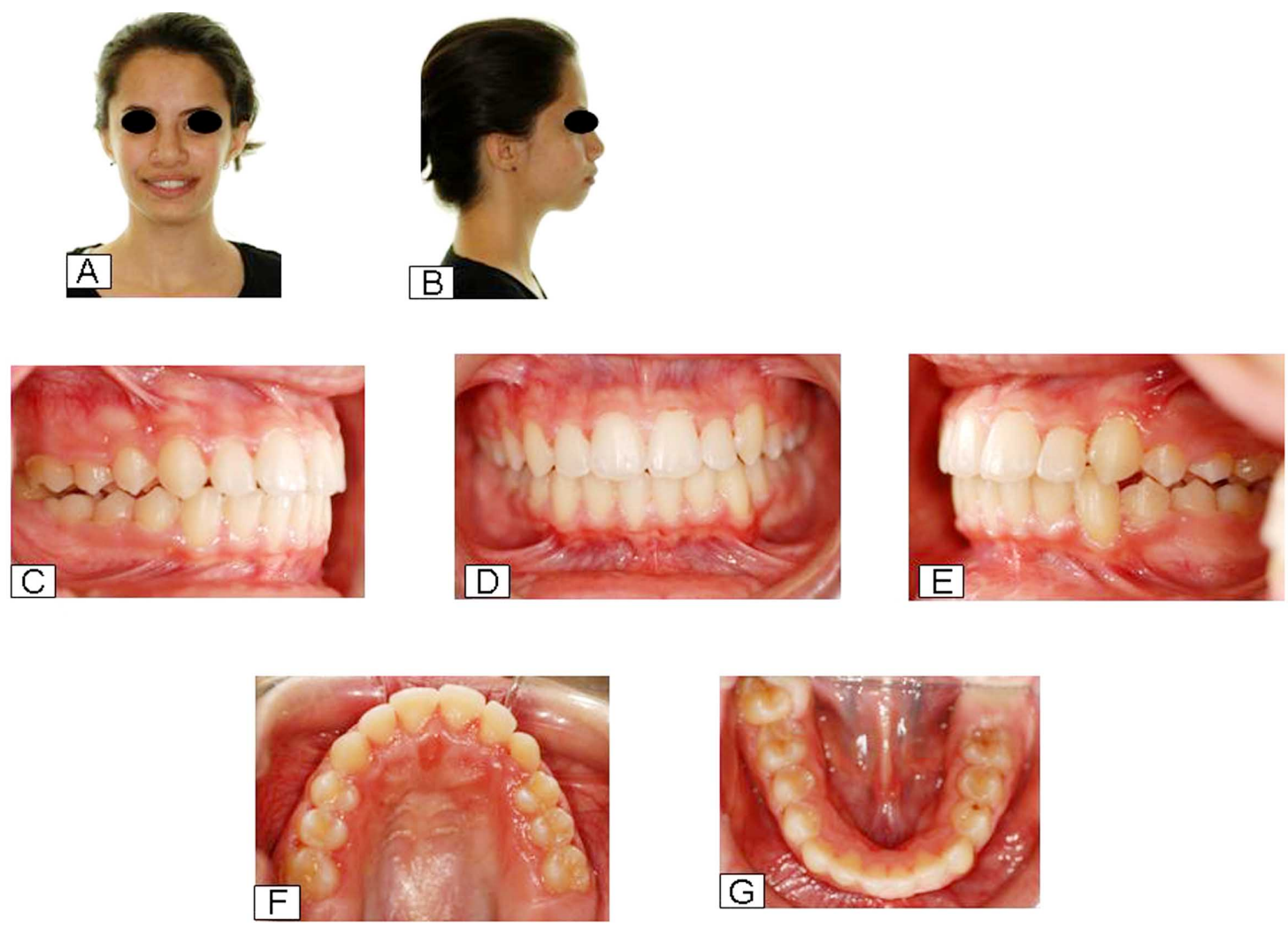

Fig. (7). Eighteen months after treatment: frontal (A) and lateral (B) views, and dental relations right side (C), frontal (D), left side (E), occlusal view of maxillary dental $\operatorname{arch}(\mathbf{F})$, and occlusal view of mandibular dental $\operatorname{arch}(\mathbf{G})$.

shaped face, preserving the facial appearance of the child was an important factor. The main concern of the family was treating the malocclusion. Both parents and child were satisfied with the facial appearance, so that any surgical approach aiming to produce an "ideal" appearance would run the risk of producing a facial esthetic pattern less acceptable to both parents and the patient. As long as severe face deformity was not present, it seems important to preserve the patient's appearance unchanged, and respect the wishes and opinions of the family. Secondly, as the SR cases present delay in dentofacial development, attempting to create additional space in the anterior mandibular region using orthopedic forces during the restricted normal growth of the child, could be beneficial to the patient, thus avoiding any surgical procedure later on.

In line with the objectives, after 20 months of slight and gradual expansion with removal appliances, the lower arch showed a satisfactory response. The mandibular dental arch had been widened, additional dental arch perimeter was gained for aligning the incisors and the transverse dentoalveolar discrepancy was corrected. Following two years of orthodontic treatment by means of fixed appliances, and despite the remaining convexity of the soft tissue profile, optimum dental occlusion and jaw relationships had been established and maintained.

\section{CONCLUSION}

This case report underlines the important contribution of orthodontic treatment in the successful management of a young girl with Silver-Russell syndrome by improving facial esthetics and normalizing dentoalveolar morphology.

\section{PATIENT'S CONSENT}

Finally, with the present document, parents, guardians and patients agree that all diagnostic records and any other related to the treatment of the patient can be used for educational and research purposes.

\section{CONFLICT OF INTEREST}

The authors confirm that this article content has no conflicts of interest.

\section{ACKNOWLEDGEMENT}

Declared none.

\section{REFERENCES}

[1] Perkins RM, Hoang-Xuan MT. The Russell-Silver syndrome: a case report and brief review of the literature. Pediatr Dermatol 2002; 19: 546-9.

[2] Duncan PA, Hall JG, Shapiro LR, Vibert BK. Three-generation dominant transmission of the Silver-Russell syndrome. Am J Med Genet 1990; 35: 245-50.

[3] Silver HK, Kiyasu W, George J, Deamer WC. Syndrome of congenital hemihypertrophy, shortness of stature, and elevated urinary gonadotropins. Pediatrics 1953; 12: 368-76.

[4] Russell A. A syndrome of intra-uterine dwarfism recognizable at birth with cranio-facial dysostosis, disproportionately short arms, and other anomalies (5 examples). Proc R Soc Med 1954; 47: 1040-4.

[5] Szalay GC. Pseudohydrocephalus in dwarfs. the Russell dwarf. J Pediatr 1963; 63: 622-33.

[6] Gareis FJ, Smith DW, Summitt RL. The Russell-Silver syndrome without asymmetry. J Pediatr 1971; 79: 775-81.

[7] Tanner JM, Lejarraga H, Cameron N. The natural history of the Silver-Russell syndrome: a longitudinal study of 39 cases. Pediatr Res 1975; 9: 611-23. 
[8] Gorlin RJ, Cohen MM, Levin LS. Syndromes of the head and neck. New York: Oxford University Press 1990: pp. 316-9.

[9] Rakover Y, Dietsch S, Ambler GR, Chock C, Thomsett M, Cowell CT. Growth hormone therapy in Silver Russell syndrome: 5 years experience of the Australian and New Zealand Growth database (OZGROW). Eur J Pediatr 1996; 155: 851-7.

[10] Price SM, Stanhope R, Garrett C, Preece MA, Trembath RC. The spectrum of Silver-Russell syndrome: a clinical and molecular genetic study and new diagnostic criteria. Med Genet 1999; 36: 83742.

[11] Abraham E, Altiok H, Lubicky JP. Musculoskeletal manifestations of Russell-Silver syndrome. J Pediatr Orthop 2004; 24: 552-64.

[12] Taussig LM, Braunstein GD, White BJ, Christiansen RL. SilverRussell dwarfism and cystic fibrosis in a twin. Endocrine, chromosomal, dermatoglyphic, and craniofacial studies. Am J Dis Child 1973; 125: 495-503.
[13] Cullen CL, Wesley RK. Russell-Silver syndrome: microdontia and other pertinent oral findings. ASDC J Dent Child 1987; 54: 201-4.

[14] Kotilainen J, Hölttä P, Mikkonen T, Arte S, Sipilä I, Pirinen S. Craniofacial and dental characteristics of Silver-Russell syndrome. Am J Med Genet 1995; 56: 229-36.

[15] Bergman A, Kjellberg H, Dahlgren J. Craniofacial morphology and dental age in children with Silver-Russell syndrome. Orthod Craniofac Res 2003; 6: 54-62.

[16] Bedi R, Moody GH. A primary double molar tooth in a child with Russell-Silver syndrome. Br Dent J 1991; 171: 284-6.

[17] Rubenstein LK, Vitsky PL. Dental management of patients with Russell-Silver syndrome. J Pedod 1988; 12: 215-9.

[18] Subklew D, Hock S. Tooth and jaw development in the SilverRussel syndrome. Fortschr Kieferorthop 1990; 51: 378-83.

[19] Kisnisci RS, Fowel SD, Epker BN. Distraction osteogenesis in Silver Russell syndrome to expand the mandible. Am J Orthod Dentofacial Orthop 1999; 116: 25-30.

(c) Ioannidou-Marathiotou et al.; Licensee Bentham Open .

This is an open access article licensed under the terms of the Creative Commons Attribution Non-Commercial License (http://creativecommons.org/licenses/by-nc/3.0/) which permits unrestricted, non-commercial use, distribution and reproduction in any medium, provided the work is properly cited. 